\title{
Vacuum-Assisted Closure Versus On-demand Relaparotomy in Patients With Secondary Peritonitis - the VACOR Trial: Protocol for a Randomized Controlled Trial
}

\section{Pooya Rajabaleyan ( $\sim$ Pooya.rajabaleyan@rsyd.dk)}

Odense University Hospital

Jens Michaelsen

Odense University Hospital

Uffe Tange Holst

Odense University Hospital

Sören Möller

OPEN, Odense University Hospital, University of Southern Denmark

Palle Toft

Odense University Hospital

Niels Qvist

Odense University Hospital

Mark Bremholm Ellebaek

Odense University Hospital

Jan Luxhøi

Hospital of Southwest Jutland

Musa Buyukuslu

University of Southern Denmark

Aske Mathias Bohm

Holbæk Sygehus

Lars Borly

Holbæk Sygehus

Gabriel Sandblom

Stockholm South General Hospital

Martin Kobborg

Kolding Hospital

Kristian Aagaard Poulsen

Odense University Hospital

Uffe Schou Løve

Regionshospitalet Viborg 


\section{Sophie Ovesen}

Regionshospitalet Viborg

Christoffer Grant Sølling

Regionshospitalet Viborg

Birgitte Mørch Søndergaard

Regionshospitalet Viborg

Lasse Persson

Hospital of Southwest Jutland

Michael Festersen Nielsen

Hospital of Southwest Jutland

Marianne Lund Lomholt

Aarhus University Hospital

Dorthe Ritz Møller

Aarhus University Hospital

\section{Study protocol}

Keywords: Secondary peritonitis, Faecal peritonitis, Vacuum-assisted closure, Primary abdominal closure, Relaparotomy on-demand

Posted Date: February 23rd, 2022

DOI: https://doi.org/10.21203/rs.3.rs-1374825/v1

License: (c) (1) This work is licensed under a Creative Commons Attribution 4.0 International License. Read Full License 


\section{Abstract}

\section{Background}

Secondary peritonitis is a severe condition with a reported mortality of $20-32 \%$. Vacuum-assisted closure (VAC) or primary closure with relaparotomy on-demand (ROD) are the accepted treatment modalities. However, no randomised controlled trial has been conducted comparing the potential benefits and disadvantages of the two methods.

\section{Methods}

This study will be a randomised controlled multicentre trial, including patients aged 18 years or older with purulent or faecal peritonitis confined to up to two of the four abdominal quadrants, originating from the small intestine, colon or rectum. Randomisation will be web-based to either primary closure with ROD or VAC in blocks of 2, 4 and 6 . The primary endpoint is peritonitis-related complications and comprehensive Complication Index (CCl) within 30 or 90 days and one year after index operation. Secondary outcomes are mortality after 30 or 90 days and one year; quality of life assessment by (SF-36) after three and 12 months, the development of incisional hernia after 12 months as assessed by clinical examination and CT-scanning and healthcare resource utilisation. With an estimated superiority of $15 \%$ in the primary outcome for VAC, a total of 340 patients must be included. Hospitals in Denmark and Europe will be invited to participate.

\section{Discussion}

There is no robust evidence for choosing either open abdomen with VAC-treatment or primary closure with relaparotomy on demand in patients with secondary peritonitis. The present study has the potential to answer this important clinical question.

Trial Registration

The study protocol has been registered at clinicaltrials.gov (NCT03932461).

Version

Protocol version 1.0, 9 January 2022.

\section{Background}

Perforation of the gastrointestinal tract is the most common cause of secondary peritonitis $(1,2)$. The underlying conditions may be appendicitis, anastomotic dehiscence, perforated diverticulitis, intestinal ischemia or gastroduodenal ulcer, with trauma being the most common (3-7). Faecal peritonitis is associated with high mortality and morbidity rate with a reported 28-days mortality up to $20 \%$, increasing to $32 \%$ at six-month follow-up (8). Age, comorbidity, time to intervention and the extent of peritonitis are 
important risk factors $(7,9-14)$. A prerequisite for non-failure is sufficient source control, antibiotics and postoperative intensive care treatment (15-19).

Despite sufficient treatment, the risk of postoperative abdominal complications is high and several patients may undergo a reoperation (s) to reveal and treat the complications. Another risk is the development of abdominal compartment syndrome. To manage this, three different strategies may be employed: a planned relaparotomy (PR), a relaparotomy on-demand (ROD), or the open abdomen (OA) principle $(2,5,20-23)$. A randomised controlled trial on PR versus ROD in patients with secondary peritonitis due to gastrointestinal perforation, including 232 patients, showed no significant difference in 1 -year mortality (36\% vs. $29 \%$ ) and morbidity (44\% vs. $40 \%$ ) (20). ROD resulted in significantly fewer relaparotomies and lower hospital-related healthcare costs.

A guideline (19) and consensus report (24) from the World Society of Emergency Surgery recommend ROD or VAC as the preferred treatment strategies for intraabdominal infections with peritonitis and nontraumatic abdominal emergencies. The benefit of primary abdominal closure and ROD strategy is that patients do not require further scheduled operations. The risk is a delay in treatment for ongoing abdominal sepsis, other serious complications and abdominal compartment syndrome, which may be difficult to recognise clinically in the severely ill patient (25-28). Delays in treating severe complications might increase the risk of morbidity and mortality $(9,11,14)$. The advantages of VAC are a planned inspection of the abdominal cavity and the possibility to diagnose and treat potential or overt abnormalities in a timely manner. The risk is the development of entero-atmospheric fistula, difficulties in abdominal wound closure and the development of an incisional hernia $(29,30)$.

The method with VAC was initially introduced in damage control trauma surgery and has gained increasing use in the treatment of complicated intraabdominal infections $(21,31-43)$. A systematic review and meta-analysis by Atema et al. from 2015 showed an incidence of $14.6 \%$ for enteroatmospheric fistula (EAF) and $48.5 \%$ for incisional hernias in the group treated with VAC and where $82 \%$ were treated for peritonitis. The mortality varied between $21.5 \%$ and $30.0 \%$. The VAC procedure can be applied and modified in several ways. The most common are fascial traction methods (mesh mediated or non-mesh mediated), the applied vacuum pressure, the interval for changes of the VAC and several other modifications (42). The VAC treatment in the present study will be the non-mesh-mediated fascial traction with the narrowing technique. A retrospective study from our institute using this technique, including 115 patients with secondary peritonitis, found a mortality rate of $17 \%$ and EAF in $3.5 \%$; secondary closure was obtained in $92 \%$ of the patients (44).

The present study will aim to compare the postoperative results of ROD and VAC in patients with secondary peritonitis by a randomised controlled trial with peritonitis-related complications and a Comprehensive Complication Index (CCl) as the primary outcome; mortality, quality of life, the development of incisional hernia and hospital care utility and costs were the secondary outcomes.

\section{Objectives}


- Primary

- Peritonitis-related complications (Table 1) and CCl within 30 or 90 days and one year after index surgery.

- Secondary

- Mortality within 30 or 90 days and after one year

- SOFA score and C-reactive protein (CRP) measured in the first seven days after index laparotomy

- Incisional hernia rate after 12 months assessed by clinical examination and abdominal CT-scan

- Quality of life after 3 and 12 months assessed by the SF-36 questionnaire

- Hospital care utility within three months after index surgery (Table 2)

- Tertiary

- The concentration of lactate, glycerol, pyruvate, glucose and cytokines in the peritoneal fluid in a subgroup of 10 patients from each group measured by intraperitoneal microdialysis on postoperative days $0-4$

- Incisional hernia rate after three years assessed by a retrospective review of patient records

The rationale for choosing both $\mathrm{CCl}$ and peritonitis-related complications as the primary outcomes was that we could not make a meaningful sample size calculation based on $\mathrm{CCl}$ alone due to insufficient data in the literature. $\mathrm{CCl}$ would be the optimal choice as it is validated and weighted. The morbidity due to peritonitis-related complications has previously been reported in ROD (20).

\section{Methods}

\section{Study design}

A multicentre non-blinded superiority randomised controlled trial on VAC vs. ROD. Danish, as well as other European centres, will be invited to participate. The study protocol adheres to the guidelines determined in Standard Protocol Items: Recommendations for Interventional Trials (SPIRIT) (45).

The VACOR study will include three separate studies: VACOR-Main, VACOR-Microdialysis and VACORHernia.

All centres must participate in the VACOR-Main and Hernia study, with only Odense University Hospital participating in the VACOR-Microdialysis study. VACOR-Main will report on all of the primary and secondary outcomes; in VACOR-Microdialysis, a sub-study of 10 patients from each group will be included. A microdialysis catheter will be placed in the peritoneal cavity and samples of the peritoneal fluid will be collected every $6^{\text {th }}$ hour to measure the concentration of lactate, glucose, pyruvate, glycerol, cytokines (IL-1b, IL-6, IL-10, TNF-a) and metalloproteins (MMP9 and MMP8). The purpose is to investigate intraperitoneal metabolic changes and inflammatory responses in the two groups. In the VACOR-Hernia 
study, there will be a retrospective patient chart review for a hernia operation, any abdominal CT-scanning describing an incisional hernia, or an incisional hernia detected by physical examination of the abdomen three years after the index operation.

\section{In-hospital healthcare utility}

Three months after the index operation, a record review will be made to estimate the healthcare utility. All data will be retrieved from the electronic patient system and includes surgeries, total hospital stay, admissions to the ICU and radiological interventions (Table 2). For the analysis, unit costs were obtained from the Danish Health Authority. The diagnosis-related groups (DRG) will be used, which express the hospital's average operating expenses within each DRG group. To ensure comparability between centres, we will utilise the Danish costs for both Danish and international patients.

\section{Study population}

\section{Inclusion criteria}

Patients eligible for enrolment are 18+ years of age and scheduled for acute laparotomy due to suspected peritonitis originating from perforation of the small bowel, colon, or rectum. To be included, purulent, enteric, or faecal contamination in a minimum of 2 out of 4 quadrants must be confirmed.

\section{Exclusion criteria}

- Diffuse peritonitis originating from a perforation on the stomach, duodenum, gallbladder, appendix, necrotising pancreatitis, salpingitis, or peritoneal dialysis

- Primary peritonitis

- Immunocompromised (ongoing chemotherapy or prednisolone $>20 \mathrm{mg} /$ day)

- Chronic parenchymal liver disease

- Pregnancy

- Patients with end-stage disease

- Laparoscopic surgery (not converted to laparotomy)

- Acute occlusion of superior mesenteric artery

- Peritoneal carcinomatosis

- Abdominal trauma

- Lack of consent from the surgical equipoise

- Local peritonitis confined to one quadrant only

\section{Study setting}

The study will be conducted in general surgery departments, emergency departments and operating theatres. The lead centre is Odense University Hospital in Odense, Denmark, a tertiary referral academic 
medical centre. Other recruiting sites will include academic and community hospitals located in Europe, which are familiar with the interventions and willing to adhere to the treatment regimens.

\section{Randomisation}

Patients are included by a surgical equipoise followed by patient information and consent after recovery. The primary investigator from each site will be contacted by the on-call surgeon when a patient is scheduled for diagnostic laparoscopy or explorative laparotomy on suspicion of secondary peritonitis. Patients fulfilling the inclusion criteria will be randomised after consent has been obtained by the surgical equipoise (Figure 1). Centres that do not receive approval from their respective scientific ethics committee to include patients through a surgical equipoise must obtain informed and written consent obtained before randomisation. Randomisation will be web-based via (REDCap ${ }^{\circledR}$ ) in blocks of 2, 4 and 6 stratified for centre and age above or below 65 years. The justifications for stratifying according to the centre are that there might be differences in the surgical treatment, preoperative optimisation and postoperative treatment, both at the ward and on the intensive care unit (ICU), which might affect the outcome. The patients will be randomised to either abdominal closure with ROD or open abdomen with VAC according to transparent reporting of trials (CONSORT) (Figure 2). The randomisation tool, along with eligibility criteria, can be accessed through our website, www.vacor.sdu.dk.

In cases where the surgeon finds that the allocated treatment may be contraindicated or is judged to harm the patient, it will be left to the surgeon's discretion to choose the most appropriate treatment. Patients who cannot be treated according to randomisation will be analysed according to intention-totreat principles. Any eligible patient who is not included will be registered in a screening log.

\section{Interventions}

Vacuum-assisted closure

The VAC ${ }^{\circledR}$ Abdominal Dressing System (KCl Vacuum Assisted Closure, San Antonio, TX, USA) will be used (44). A video illustrating the procedure is attached in the supplementary material (Additional File 1). Intestines, including lateral aspects, are covered by the visceral protective layer. The first layer of foam is placed in the laparostoma on the visceral protective layer and must extend below the fascia at a distance of $5 \mathrm{~cm}$ from the fascial opening. Above this, a minimum of one piece of foam is folded and placed in the laparostoma. Finally, the laparostoma will be covered by the occlusive drape. A circular opening of approximately $5 \mathrm{~cm}$ in diameter will be created in the drape where the connection tubes to the vacuum pump will be placed. Simultaneously, while applying the negative pressure of $125 \mathrm{mmHg}$, the wound edges are approximated manually towards the midline. The dressing will be changed with an interval of approximately 48 hours as standard or whenever needed according to the clinical condition. Each dressing change must be performed in the operating theatre with the patient under general anaesthesia and muscle relaxation. Peritoneal fluid must be cultured at each dressing change and when the fascia is closed. The fascial closure will commence as soon as possible according to the patient's general condition judged by gastrointestinal function, renal function and a decline in inflammatory parameters, 
either in one or repeated sessions. The aim will be closure of the abdomen within a maximum of 8 days after the index operation.

The fascia closure after VAC-treatment can be according to Israelsson's principle, as described below, or at the surgeon's discretion. A staged closure may start distally, proximally, or in combination.

\section{Primary closure}

The Israelsson principle includes a running suture of the fascia with a distance of $5 \mathrm{~mm}$ between the stitches of $5 \mathrm{~mm}$ and the distance to the fascial edge of 5-10 mm. Monofilament PDS 2-0 or equivalent is used (46). The suturing is started cranially and caudally and the sutures are tied with self-locking knots. Four times as much suture material as the length of the wound must be used. The peritoneal fluid must be cultured at closure.

Relaparotomy-on demand (ROD)

The treating surgeon decides to perform a ROD and should be guided by the patient's general condition, gastrointestinal function, renal function and inflammatory parameters at daily rounds.

Microdialysis

The intraperitoneal microdialysis catheter will be placed before the abdominal closure or before applying the VAC-system. The microdialysis catheter (M-dialysis 63, Microdialysis AB, Stockholm, Sweden) will be introduced through the abdominal wall outside the laparostoma via a charrier ten split cannula and placed in the peritoneal cavity between small intestine loops. The catheter will be perfused by an isotonic perfusion fluid (Perfusion fluid CNS Dextran, Microdialysis AB, Stockholm, Sweden) via a small pump (Microdialysis CMA 106 pump, Microdialysis AB, Stockholm, Sweden) at a flow rate of $0.3 \mathrm{ml} / \mathrm{min}$. The catheter will be anchored to the skin. Samples will be collected in vials at 6 -hour intervals for the first four postoperative days. Bedside analysis for lactate, glycerol and pyruvate concentration will be made via the ISCUSflex Microdialysis Analyzer (Microdialysis AB, Stockholm, Sweden). After analysis, the samples will be stored at $-80^{\circ} \mathrm{C}$ to analyse cytokine and MMP concentrations.

\section{Postoperative patient assessment}

Immediately after index operation, the surgeon fills out the baseline form containing patient characteristics and comorbidities, aetiology of the peritonitis, surgical procedure and the complexity of the condition according to Björck's classification (47). Patients can be transferred postoperatively to the intensive care unit (ICU) or the ward at the discretion of the treating team. Upon arrival to either the ward or the ICU, Acute Physiology and Chronic Health Evaluation II (APACHE II) and sequential organ failure assessment (SOFA) scores must be obtained by the attending anaesthesiologist $(48,49)$. SOFA-scoring and routine blood samples with CRP, bilirubin, creatinine and platelets must be performed daily within the first seven days after index operation. Discharge from the ICU will be at the discretion of the attending intensivist and surgeon. 


\section{Follow-up}

At hospital discharge, the patients will be booked for follow-up after 12 months in the outpatient clinic for abdominal palpation and abdominal CT-scan with intravenous contrast and Valsalva manoeuvre. In addition, the SF-36 questionnaire will be completed at the 3- and 12-month follow-up.

\section{Data collection and participant timeline}

The pre- and perioperative assessment will consist of: baseline data (sex, age, surgery date, height, weight, body mass index, ASA score, WHO performance score, smoking, alcohol consumption, presence of comorbidities, previous abdominal surgeries and steroid use). Data for surgical findings include aetiology of disease, anatomical location of intestinal perforation, degree of contamination, surgical treatment, method of abdominal wall closure, suture material used for abdominal wall closure. Postoperative monitoring consists of SOFA, APACHE II, CRP, VAC treatment duration, unplanned VAC change and the number of laparotomies in the ROD group. A patient record review will be performed at the follow-up after one month, three months, one year and five years (Figure 3). All data will be stored in REDCap ${ }^{\circledR}$, hosted by the Odense Patient data Explorative Network (OPEN).

\section{Sample size and power}

With an expected peritonitis related complications rate of $40 \%$ in the ROD group (20) and $25 \%$ in the VAC group $(42,44)$, the desired power of $80 \%$, a significance level of 0.05 and an expected drop-out of $5 \%$ a total of 340 patients should be included. With this sample size, a 0.32 standard deviation difference in mean $\mathrm{CCl}$ between the two groups could be detected with $80 \%$ power as well.

To ensure sufficient recruitment, the study will be multicentre and European. Eight active centres have been included and two are in process. Randomisation tools along with eligibility criteria are accessible through our website. The workflow and relevant contact details appear on posters at the participating departments. Study progress will be available on the website.

\section{Statistical analysis}

Patient characteristics will be summarised with frequencies and proportions (for categorical variables) or with mean values \pm standard deviation, median values, quartiles and minimum and maximum values (for numerical variables). Categorical variables will be compared using a Fisher's exact test and continuous variables with a Wilcoxon rank-sum test.

The primary peritonitis-related complication outcome will be compared between intervention groups by the chi-squared test, reported as relative risk with a $95 \% \mathrm{Cl}$. The CCl outcome will be compared by linear regression with bootstrapped standard errors reporting the mean difference with $95 \%$ confidence intervals. 
A superiority and non-inferiority analysis VAC treatment against primary closure with ROD will be performed. A non-inferiority margin of $5 \%$ was reported for peritonitis-related complications.

A univariate analysis will be performed on the individual complication types (abscess, leakage, etc.) and complications as a whole (peritonitis related complications and $\mathrm{CCl}$ ). Fisher's exact or chi-square test will be used to compare the treatments depending on the number of observations.

Adjusted analysis by logistic regression will be performed for complications as a whole and for the individual complications as an outcome, which will be adjusted for age, performance status and comorbidity. The above analyses will also be performed as a subgroup analysis where patients with APACHE-II score $>10$ will be included. This evaluates VAC and ROD in the most seriously ill portion of the patient population.

The hospital healthcare utility and average treatment costs are compared between the treatment groups. The resource use will be reported as the mean difference with $95 \%$ confidence intervals $(\mathrm{Cl})$ compared by linear regression. In case of deviations from normality assumptions, bootstrapping with 1000 repetitions will be performed. Finally, the proportion of patients who experience radiological, acute operations will be compared by binomial regression estimating relative risk (RR) with $95 \% \mathrm{Cl}$.

The interim analysis will be performed at $25 \%, 50 \%$ and $75 \%$ of recruited patients on the primary outcome after 30-days to detect significant differences between groups at the earliest possible time, ultimately leading to the termination of the study. We have adjusted our power calculation to the interim analyses using the O'Brian-Flemming method. The study group will have access to the results of the interim analyses and may make the final decision to terminate the study.

All of the above analyses will be performed as both intention-to-treat (patients will be analysed according to their randomisation group) and per-protocol analysis (what actually happened). The main analyses will be performed as complete case analyses. Multiple imputations will impute missing values in a supplementary analysis, including baseline characteristics as predictors.

$P$ values $<0.05$ will be considered statistically significant. Statistical calculations will be performed using Stata software (version 15, Stata Corp LP, Texas, USA).

In the VACOR-Microdialysis sub-study, the parameters will be compared using descriptive statistics for continuous and discrete variables. Repeated measurement across time points will be compared by mixedeffects regression models, including the interaction between time points and operation method and a random intercept for each patient. In addition, normality assumptions will be graphically assessed using quantile-quantile plots.

\section{Ethics and consent to participate}

The study will be conducted in accordance with the Declaration of Helsinki and complies with current GDPR recommendations. The regional Danish Medical Ethics Committee has approved the study to 
include patients in the acute setting with temporary consent by a surgical equipoise followed by patient information and consent after recovery. The surgical equipoise must not have any personal interest in the experiment, have experience, or have knowledge about the disease and the risks and benefits of the treatments and must be indifferent to the therapeutic value of the two interventions. The rationale for choosing this inclusion model was that the subjects requiring immediate surgical intervention are partially or entirely incapable of receiving and understanding the information. The severity of the condition does not allow time for third-party authorisation. Both treatment regimens are accepted, safe and widely used for this patient group. After the convalescence, patients will be informed about the project and consent will be obtained. In instances where the patients do not survive before regaining a habitual state, surrogate consent will be obtained. The patient can withdraw from the experiment at any time without having to explain their reasons.

Patients in Denmark are covered by national insurance (Patienterstatningen), international centres will use country-specific insurance regulations. The study is investigator-initiated without economic interest to manufacturers or others involved in the investigation. No financial resources will be provided to the trial participants. Participating centres will receive the amount of 4000 Danish Krone per included patient yearly to cover the CT-scan of the abdomen and follow-up at the outpatient clinic.

The final data set will be available to the project owner and data assessor. Data can be shared in an anonymised form after an approved agreement on request. The primary investigator is responsible for data collection and handling. Unexpected adverse events and protocol modifications must be reported to the regional ethics committee.

\section{Dissemination policy}

The study results will be published in scientific international peer-review journals and presented at relevant conferences. Results will be available to participants, healthcare professionals, the public and other relevant groups in an anonymous patient format. The study protocol will be publicly accessible. Authorship eligibility adheres to Vancouver conventions guidelines.

\section{Discussion}

The VACOR trial addresses several important unanswered clinical questions in the surgical treatment of complicated intrabdominal infections with special reference to the choice of primary abdominal closure with ROD or the open abdomen with VAC treatment.

As well as our study, another randomised multicentre trial, the COOL study (50), is actively recruiting patients with secondary peritonitis to either VAC or primary closure. The primary endpoint is the 90-day mortality rate. In the intervention arm receiving the open management, the VAC treatment is not standardised as in our trial. To ensure the uniformity of intervention, we have produced a video where the application of the VAC system is demonstrated in a step-by-step manner, as well as providing training for centres not familiar with the technique. The COOL study includes only severely ill patients, assessed by 
physiological scores and secondary peritonitis originating from the lower- and upper gastrointestinal tract, gallbladder and adnexa. The current study includes patients with secondary peritonitis from the lower gastrointestinal tract with purulent, enteric, or faecal contamination in a minimum of two out of four abdominal quadrants irrespective of the patient's general condition. Our study and the COOL study utilise inclusion via a surgical equipoise, ensuring that a high fraction of eligible patients will be included. A limitation of the current study is that the power calculation is based on peritonitis-related complications and not the $\mathrm{CCl}$-index due to the literature lacking explicit results for VAC and ROD.

In some conditions such as severely complicated peritonitis, second look for ischemia and septic shock, where patients have substantial visceral oedema with high risks of abdominal compartment syndrome, establishing an OA with VAC may be preferred $(5,17,19,24)$. According to intention to treat and perprotocol principles, these patients will be included in the present study. The OA with VAC treatment may have several benefits, including drainage of residual infection, preventing intrabdominal compartment syndrome and the timely treatment of complications. The disadvantages are incisional hernia and EAF $(23,42,44,51-55)$. A recent review of temporary abdominal closure techniques found a higher incidence of EAF in septic than non-septic patients ( $12.1 \%$ vs. $3.7 \%$, respectively) (56). A large cohort study by Coccolini et al., including 649 patients treated with OA where most patients had peritonitis, could not confirm that peritonitis or temporary abdominal closure with or without negative pressure was related to the incidence of EAF (57). In systematic reviews with meta-analyses, non-randomised studies have shown that VAC is the safest of all temporary abdominal closure techniques $(21,31-43)$.

In a study including patients with severe secondary peritonitis, patients were randomised to OA with nonresorbable polypropylene mesh versus primary closure with ROD (58). The study was discontinued at the first interim. The study showed an insignificant higher mortality risk in the OA group of $55 \%$ compared to $30 \%$ in the ROD group. However, there was a relative risk of 1.83 and an odds ratio of 2.85 in the OA group. Hence, the authors concluded that there was a tendency towards a better outcome in the ROD group.

Animal and in silico studies suggest that VAC treatment suppresses systemic inflammatory reaction and prevents multi-organ failure by draining the peritoneal fluid $(59,60)$. In a small animal study comparing VAC to passive drainage after inducing abdominal sepsis, the mortality rate was $17 \%$ versus $50 \%$. This difference was not statistically significant $(p=0.19)$, likely due to the small number of included animals (60). In the only human RCT, levels of plasma and peritoneal cytokines in patients with abdominal trauma and intrabdominal sepsis were compared (61). Participants were allocated to Barker's or vacuum pack. The study revealed no significant difference in bio-mediator levels or peritoneal drainage. However, a significant difference was observed in 90 -day mortality $(21.7 \%$ versus $50 \%$ ) in favour of the VAC group. There are no human RCT studies comparing bio-mediators in VAC versus primary closure with ROD.

The evaluation of the ROD strategy can face some difficulties. The literature suggests that progressive or persistent organ failure in the early postoperative phase are the best indicators for positive findings and ongoing infection $(20,26,62)$. The choice of relaparotomy is often subjective, based on local guidelines 
and personal experiences (25-28). In a randomised study of secondary peritonitis, 112 patients were included in the ROD arm and 113 in the planned relaparotomy arm (20). A total of $42 \%$ of patients in the ROD arm received relaparotomies, $71 \%$ had negative findings and $29 \%$ had positive findings at the relaparotomy, respectively.

\section{Conclusions}

There is no robust evidence for choosing either open abdomen with VAC-treatment or primary closure with relaparotomy on demand in patients with secondary peritonitis. The present study has the potential to answer this important clinical question.

\section{Trial status}

Recruitment has been active since June 2020 and is estimated to be completed in 2024-2025.

\section{Abbreviations}

VAC $=$ Vacuum-assisted closure

$\mathrm{PR}=$ Planned relaparotomy

ROD = Relaparotomy "on-demand"

$\mathrm{CCl}=$ Comprehensive complication index

SF-36 $=$ Short form survey 36

$\mathrm{OA}=$ Open abdomen

$\mathrm{EAF}=$ Enteroatmospheric fistula

$\mathrm{CT}=$ Computed tomography

$\mathrm{CRP}=$ C-reactive protein

$\mathrm{Cl}=$ Confidence interval

OPEN = Odense Patient data Explorative Network

ASA = American Society of Anesthesiology

APACHE II = Acute Physiology and Chronic Health Evaluation II

SOFA = Sequential Organ Failure Assessment

$\mathrm{ICU}=$ Intensive care unit 
DRG = Diagnosis-related groups

\section{Declarations}

\section{Consent for publication}

Not applicable.

\section{Availability of data and materials}

On request, data can be shared in an anonymised form if a data processor agreement is obtained.

\section{Competing interests}

The primary investigator and collaborators have no financial interest in the trial.

\section{Funding}

The study is founded by the University of Southern Denmark, Region of Southern Denmark and Novo Nordisk Foundation. Trial Sponsor: University of Southern Denmark, Campusvej 55, 5230 Odense M, Denmark, Email: sdu@sdu.dk, Region of Southern Denmark, Damhaven 12, 7100 Vejle, Denmark and Novo Nordisk Foundation, Tuborg Havnevej 19, 2900 Hellerup, Denmark, Email: info@novonordiskfonden.dk. The sponsors have no influence on the study design or interpretation of data.

\section{Authors' contributions}

PR, JM, UTH, PT, NQ and MBE designed the trial and drafted the protocol. SM contributed to the power calculation and statistical design. JL, MB, AB, LB, GS, MK, KAP, USL, SO, CG, BM, LP, MFN, MLL and DRM discussed and critiqued the data and its interpretation. All authors read and approved the final manuscript.

\section{References}

1. Malangoni MA, Inui T. Peritonitis - The Western experience. Vol. 1, World J Emerg Surg. 2006;1:25.

2. Pieracci FM, Barie PS. Management of severe sepsis of abdominal origin. Scand J Surg. 2007;96(3):184-96.

3. Ordoñez CA, Puyana JC. Management of peritonitis in the critically ill patient. Surg Clin North Am. 2006;86(6):1323-49.

4. Mulari K, Leppäniemi A. Severe secondary peritonitis following gastrointestinal tract perforation. Scand J Surg. 2004;93(3):204-8.

5. Sartelli M, Catena F, di Saverio S, Ansaloni L, Malangoni M, Moore EE, et al. Current concept of abdominal sepsis: WSES position paper. Vol. 9, World Journal of Emergency Surgery. 2014. 
6. Gauzit R, Péan Y, Barth X, Mistretta F, Lalaude O. Epidemiology, management and prognosis of secondary non-postoperative peritonitis: A French prospective observational multicentre study. Surgical Infections. 2009;10(2):119-127.

7. Sartelli M, Catena F, Ansaloni L, Leppaniemi A, Taviloglu K, van Goor H, et al. Complicated intraabdominal infections in Europe: A comprehensive review of the CIAO study. World J Emerg Surg. 2012;7(1):36.

8. Tridente A, Clarke GM, Walden A, McKechnie S, Hutton P, Mills GH, et al. Patients with faecal peritonitis admitted to European intensive care units: an epidemiological survey of the GenOSept cohort. Intens Care Med. 2014;40(2):202-10. Available from: https://doi.org/10.1007/s00134-0133158-7

9. Anaya DA, Nathens AB. Risk factors for severe sepsis in secondary peritonitis. Surg Infect. 2003;4(4):355-362.

10. Bohnen JMA, Mustard RA, Oxholm SE, Schouten BD. APACHE II Score and abdominal sepsis: A prospective study. Arch Surg. 1988;123(2):225-229.

11. Ohmann C, Wittmann DH, Wacha H. Prospective evaluation of prognostic scoring systems in peritonitis. Peritonitis Study Group. Eur J Surg. 1993;159(5):267-274.

12. Wacha H, Hau T, Dittmer R, Ohmann C, Aeberhard A, Billing A, et al. Risk factors associated with intraabdominal infections: A prospective multicentre study. Langenbeck Arch Surg. 1999;384(1):2432.

13. Hynninen M, Wennervirta J, Leppäniemi A, Pettilä V. Organ dysfunction and long-term outcome in secondary peritonitis. Langenbeck Arch Surg. 2008;393(1):81-86.

14. Tolonen M, Sallinen V, Mentula P, Leppäniemi A. Preoperative prognostic factors for severe diffuse secondary peritonitis: a retrospective study. Langenbeck Arch Surg. 2016 Aug;401(5):611-7. Available from: https://doi.org/10.1007/s00423-016-1454-8

15. Tellor B, Skrupky LP, Symons W, High E, Micek ST, Mazuski JE. Inadequate source control and inappropriate antibiotics are key determinants of mortality in patients with intra-abdominal sepsis and associated bacteraemia. Surg Infect. 2015;16(6):785-793.

16. Sartelli M, Catena F, Ansaloni L, Coccolini F, Corbella D, Moore EE, et al. Complicated intra-abdominal infections worldwide: The definitive data of the CIAOW Study. World J Emerg Surg. 2014;9(1):37.

17. Sartelli M, Catena F, Abu-Zidan FM, Ansaloni L, Biff WL, Boermeester MA, et al. Management of intraabdominal infections: Recommendations by the WSES 2016 consensus conference. World J Emerg Surg. 2017;12:22.

18. Ross JT, Matthay MA, Harris HW. Secondary peritonitis: Principles of diagnosis and intervention. BMJ. 2018;361:k1407.

19. Sartelli M, Chichom-Mefire A, Labricciosa FM, Hardcastle T, Abu-Zidan FM, Adesunkanmi AK, et al. The management of intra-abdominal infections from a global perspective: 2017 WSES guidelines for management of intra-abdominal infections. World J Emerg Surg. 2017;12. 
20. van Ruler O, Mahler CW, Boer KR, Reuland EA, Gooszen HG, Opmeer BC, de Graaf PW, Lamme B, Gerhards MF, Steller EP, van Till JW, de Borgie CJ, Gouma DJ, Reitsma JB, Boermeester MA; Dutch Peritonitis Study Group. Comparison of on-demand vs planned relaparotomy strategy in patients with severe peritonitis: A randomised trial. JAMA. 2007 Aug 22;298(8):865-72. Available from: http://dx.doi.org/10.1001/jama.298.8.865

21. Turza KC, Campbell CA, Rosenberger LH, Politano AD, Davies SW, Riccio LM, et al. Options for closure of the infected abdomen. Surg Infect. 2012;13(6):343-351.

22. Cirocchi R, Birindelli A, Biffl WL, Mutafchiyski V, Popivanov G, Chiara O, et al. What is the effectiveness of the negative pressure wound therapy (NPWT) in patients treated with open abdomen technique? A systematic review and meta-analysis. J Trauma Acute Care Surg. 2016;81(3):575-584.

23. Lamme B, Boermeester MA, Belt EJT, van Till JWO, Gouma DJ, Obertop H. Mortality and morbidity of planned relaparotomy versus relaparotomy on demand for secondary peritonitis. Brit J Surg. 2004;91(8):1046-1054.

24. Coccolini F, Montori G, Ceresoli M, Catena F, Moore EE, Ivatury R, et al. The role of open abdomen in non-trauma patient: WSES Consensus Paper. Vol. 12, World J Emerg Surg. 2017;12.

25. van Ruler O, Kiewiet JJS, Boer KR, Lamme B, Gouma DJ, Boermeester MA, et al. Failure of available scoring systems to predict ongoing infection in patients with abdominal sepsis after their initial emergency laparotomy. BMC Surgery. 2011(11):38.

26. Hutchins RR, Gunning MP, Lucas DN, Allen-Mersh TG, Soni NC. Relaparotomy for suspected intraperitoneal sepsis after abdominal surgery. World J Surg. 2004;28(2):137-141.

27. Bader FG, Schröder M, Kujath P, Muhl E, Bruchi HP, Eckmann C. Diffuse postoperative peritonitis Value of diagnostic parameters and impact of early indication for relaparotomy. European $\mathrm{J}$ Med Res. 2009;14(11):491-496.

28. van Ruler O, Lamme B, Gouma DJ, Reitsma JB, Boermeester MA. Variables associated with positive findings at relaparotomy in patients with secondary peritonitis. Crit Care Med. 2007;35(2):468-476.

29. Demetriades D, Salim A. Management of the open abdomen. Surg Clin North Am. 2014;94(1):131-53. Available from: https://www.sciencedirect.com/science/article/pii/S003961091300159X? via\%3Dihub

30. Regner JL, Kobayashi L, Coimbra R. Surgical strategies for management of the open abdomen. World J Surg. 2012 Mar;36(3):497-510. Available from: https://doi.org/10.1007/s00268-011-1203-7

31. Horwood J, Akbar F, Maw A. Initial experience of laparostomy with immediate vacuum therapy in patients with severe peritonitis. Ann Royal Coll Surg England. 2009;91(8):681-687.

32. Amin Al, Shaikh IA. Topical negative pressure in managing severe peritonitis: A positive contribution? World J Gastroenterol. 2009;15(27):3394-3397.

33. Tolonen M, Mentula P, Sallinen V, Rasilainen S, Bäcklund M, Leppäniemi A. Open abdomen with vacuum-assisted wound closure and mesh-mediated fascial traction in patients with complicated 
diffuse secondary peritonitis: A single-centre 8-year experience. J Trauma Acute Care Surg. 2017;82(6):1100-1105.

34. Wondberg D, Larusson HJ, Metzger U, Platz A, Zingg U. Treatment of the open abdomen with the commercially available vacuum-assisted closure system in patients with abdominal sepsis: Low primary closure rate. World J Surg. 2008;32(12):2724-2729.

35. Plaudis H, Rudzats A, Melberga L, Kazaka I, Suba O, Pupelis G. Abdominal negative-pressure therapy: A new method in countering abdominal compartment and peritonitis - prospective study and critical review of literature. Ann Intens Care. 2012;2(S1):S23.

36. Perez D, Wildi S, Demartines N, Bramkamp M, Koehler C, Clavien PA. Prospective evaluation of vacuum-assisted closure in abdominal compartment syndrome and severe abdominal sepsis. J Am Coll Surg. 2007;205(4):586-592.

37. Fortelny RH, Hofmann A, Gruber-Blum S, Petter-Puchner AH, Glaser KS. Delayed closure of open abdomen in septic patients is facilitated by combined negative pressure wound therapy and dynamic fascial suture. Surg Endosc. 2014;28(3):735-740.

38. Schmelzle M, Alldinger I, Matthaei H, Aydin F, Wallert I, Eisenberger CF, et al. Long-term vacuumassisted closure in open abdomen due to secondary peritonitis: a retrospective evaluation of a selected group of patients. Dig Surg. 2010;27(4):272-278.

39. Mutafchiyski VM, Popivanov GI, Kjossev KT, Chipeva S. Open abdomen and VACâ in severe diffuse peritonitis. J Royal Army Med Corps. 2016;162(1):30-34. Available from: http://jramc.bmj.com/content/162/1/30.abstract

40. Pliakos I, Papavramidis TS, Mihalopoulos N, Koulouris H, Kesisoglou I, Sapalidis K, et al. Vacuumassisted closure in severe abdominal sepsis with or without retention sutured sequential fascial closure: A clinical trial. Surgery. 2010;148(5):947-953.

41. Rausei S, Amico F, Frattini F, Rovera F, Boni L, Dionigi G. A Review on vacuum-assisted closure therapy for septic peritonitis open abdomen management. Surg Technol Int. 2014;25:68-72.

42. Atema JJ, Gans SL, Boermeester MA. Systematic review and meta-analysis of the open abdomen and temporary abdominal closure techniques in non-trauma patients. World J Surg. 2015;39(4):912925.

43. Bertelsen CA, Fabricius R, Kleif J, Kristensen B, Gögenur I. Outcome of negative-pressure wound therapy for open abdomen treatment after nontraumatic lower gastrointestinal surgery: Analysis of factors affecting delayed fascial closure in 101 patients. World J Surg. 2014;38(4):774-781.

44. Hougaard HT, Ellebaek M, Holst UT, Qvist N. The open abdomen: Temporary closure with a modified negative pressure therapy technique. Int Wound J. 2014;11(S1):13-16.

45. Chan AW, Tetzlaff JM, Gøtzsche PC, Altman DG, Mann H, Berlin JA, et al. SPIRIT 2013 explanation and elaboration: guidance for protocols of clinical trials. BMJ. 2013;346:e7586.

46. Israelsson LA, Millbourn D. Closing midline abdominal incisions. Langenbeck Arch Surg. 2012;397.

47. Björck M, Kirkpatrick AW, Cheatham M, Kaplan M, Leppäniemi A, de Waele JJ. Amended classification of the open abdomen. Scand J Surg. 2016;105(1):5-10. 
48. Knaus WA, Zimmerman JE, Wagner DP, Draper EA, Lawrence DE. APACHE-acute physiology and chronic health evaluation: a physiologically based classification system. Crit Care Med.

1981;9(8):591-597.

49. Vincent JL, Moreno R, Takala J, Willatts S, de Mendonça A, Bruining H, et al. The SOFA (Sepsisrelated Organ Failure Assessment) score to describe organ dysfunction/failure. Intens Care Med. 1996;22(7):707-710.

50. Kirkpatrick AW, Coccolini F, Ansaloni L, Roberts DJ, Tolonen M, McKee JL, et al. Closed or Open after Source Control Laparotomy for Severe Complicated Intra-Abdominal Sepsis (the COOL trial): Study protocol for a randomised controlled trial. World J Emerg Surg. 2018;13(1):26.

51. Sartelli M, Abu-Zidan FM, Ansaloni L, Bala M, Beltrán MA, Biffl WL, et al. The role of the open abdomen procedure in managing severe abdominal sepsis: WSES position paper. World J Emerg Surg. 2015;10:35.

52. Trevelyan SL, Carlson GL. Is TNP in the open abdomen safe and effective? J Wound Care. 2009;18(1):24-25.

53. Rao M, Burke D, Finan PJ, Sagar PM. The use of vacuum-assisted closure of abdominal wounds: A word of caution. Colorect Dis. 2007;9(3):266-268.

54. Mintziras I, Miligkos M, Bartsch DK. High risk of fistula formation in vacuum-assisted closure therapy in patients with open abdomen due to secondary peritonitis-a retrospective analysis. Langenbeck Arch Surg. 2016;401(5):619-625.

55. Bradley MJ. Independent predictors of enteric fistula and abdominal sepsis after damage control laparotomy. JAMA Surg. 2013;148(10):947-954.

56. Bruhin A, Ferreira F, Chariker M, Smith J, Runkel N. Systematic review and evidence-based recommendations for the use of negative pressure wound therapy in the open abdomen. International Journal of Surgery. 2014;12(10):1105-1114.

57. Coccolini F, Ceresoli M, Kluger Y, Kirkpatrick A, Montori G, Salvetti F, et al. Open abdomen and enteroatmospheric fistulae: An interim analysis from the International Register of Open Abdomen (IROA). Injury. 2019;50(1):160-166.

58. Robledo FA, Luque-De-León E, Suárez R, Sánchez P, De-La-Fuente M, Vargas A, et al. Open versus closed management of the abdomen in the surgical treatment of severe secondary peritonitis: $A$ randomised clinical trial. In: Surgical Infections. 2007;8(1):63-72.

59. Emr B, Sadowsky D, Azhar N, Gatto LA, An G, Nieman GF, et al. Removal of inflammatory ascites is associated with dynamic modification of local and systemic inflammation along with prevention of acute lung injury: In vivo and in silico studies. Shock. 2014;41(4):317-323.

60. Kubiak BD, Albert SP, Gatto LA, Snyder KP, Maier KG, Vieau CJ, et al. Peritoneal negative pressure therapy prevents multiple organ injury in a chronic porcine sepsis and ischemia/reperfusion model. Shock. 2010;34(5):525-534.

61. Kirkpatrick AW, Roberts DJ, Faris PD, Ball CG, Kubes P, Tiruta C, et al. Active negative pressure peritoneal therapy after abbreviated laparotomy: The intraperitoneal vacuum randomised controlled 
trial. Ann Surg. 2015;262(1):38-46.

62. Lamme B, Mahler CW, van Ruler O, Gouma DJ, Reitsma JB, Boermeester MA. Clinical predictors of ongoing infection in secondary peritonitis: Systematic review. World J Surg. 2006;30(12):2170-2181.

\section{Tables}

Table 1: Peritonitis related complications

\section{Disease-Related Major Morbidity Needing Readmission and Conservative Treatment but Not Surgery}

- Fistula: non-anatomical connection between intestine and cutis, communication between GI tract and external atmosphere or between 2 hollow organs

- Wound dehiscence/incisional hernia with obstruction: full-thickness discontinuity in the abdominal wall with bulging of abdominal content

- Abscess needing percutaneous drainage: pus-containing non-pre-existing cavity confirmed by positive Gram stain or culture

- Renal failure: urine production $<500 \mathrm{~mL} / 24 \mathrm{~h}$ with rising levels of blood urea nitrogen and creatinine combined with dehydration (decreased circulating volume with elevated haematocrit needing intravenous rehydration) based on inadequate oral intake, nausea/vomiting, or both (only when needing readmission)

- Myocardial infarction (electrocardiogram and enzyme changes suggestive of myocardial infarction or needing admission to coronary care unit), pulmonary embolus (ventilation-perfusion mismatch on lung scintigraphy), or cerebrovascular accident (ischemic or non-ischemic with persistent paresis or paralysis without previous history)

- Gastric or duodenal bleeding: needing endoscopic treatment or embolisation therapy

- Respiratory failure due to pneumonia, pleural effusion, or pulmonary oedema and needing oxygen therapy or mechanical ventilation

- Urosepsis: urinary tract infection with positive urine and blood cultures and circulatory shock

\section{Disease-Related Major Morbidity Needing Surgical Intervention During First Admission or Readmission}

- Incisional hernia: full-thickness discontinuity in abdominal wall with bulging of abdominal contents with or without obstruction with disabling concerns interfering with daily activities

- Bowel obstruction or herniation due to intra-abdominal adhesions: diagnosis must be confirmed during surgery

- Burst abdomen: complete midline or transverse discontinuity in abdominal wall

- Abdominal compartment syndrome: intra-abdominal hypertension $\geq 25 \mathrm{~mm} \mathrm{Hg}$ with tense abdomen and with increasing respiratory failure, renal failure, or both, measured by the urinary bladder pressure method (modified Burch criteria) 
- Fistula: non-anatomical connection between intestine and cutis, communication between GI tract and external atmosphere or between 2 hollow organs

- Intra-abdominal bleeding: only when septic bleeding after index laparotomy or relaparotomy or surgical bleeding after relaparotomy but not after index laparotomy

- Intra-abdominal haematoma needing surgical evacuation

- Perforation of visceral organ confirmed at surgery

- Anastomotic leakage: anastomotic leak on contrast imaging needing surgery or contrast-enhanced computed tomography scan, confirmed at relaparotomy

- Ischemia or necrosis of a visceral organ: critically reduced blood flow to an intraabdominal organ causing tissue loss, confirmed at pathological examination

- Enterostomy dysfunction due to prolapse, stenosis, or retraction

- Gastric or duodenal ulcer bleeding needing intervention of any type

Reference table 1: van Ruler O, Mahler CW, Boer KR, Reuland EA, Gooszen HG, Opmeer BC, de Graaf PW, Lamme B, Gerhards MF, Steller EP, van Till JW, de Borgie CJ, Gouma DJ, Reitsma JB, Boermeester MA; Dutch Peritonitis Study Group. Comparison of on-demand vs planned relaparotomy strategy in patients with severe peritonitis: A randomised trial. JAMA. 2007 Aug 22;298(8):865-72. Available from: http://dx.doi.org/10.1001/jama.298.8.865

Table 2: Health care utility

Length of admission at ICU (Total number of days in a three-month period)

Length of admission at ward (Total number of days in a three-month period)

VAC - Time from index operation to primary closure

Total amount of VAC dressing changes (number of times)

Number of scheduled VAC changes

Number of re-operations with VAC

Number of re-operations

Number of radiologic interventions during admission(s)

Number of computed tomography scans after index operation

Number of days alive outside the ICU in a three-month period 


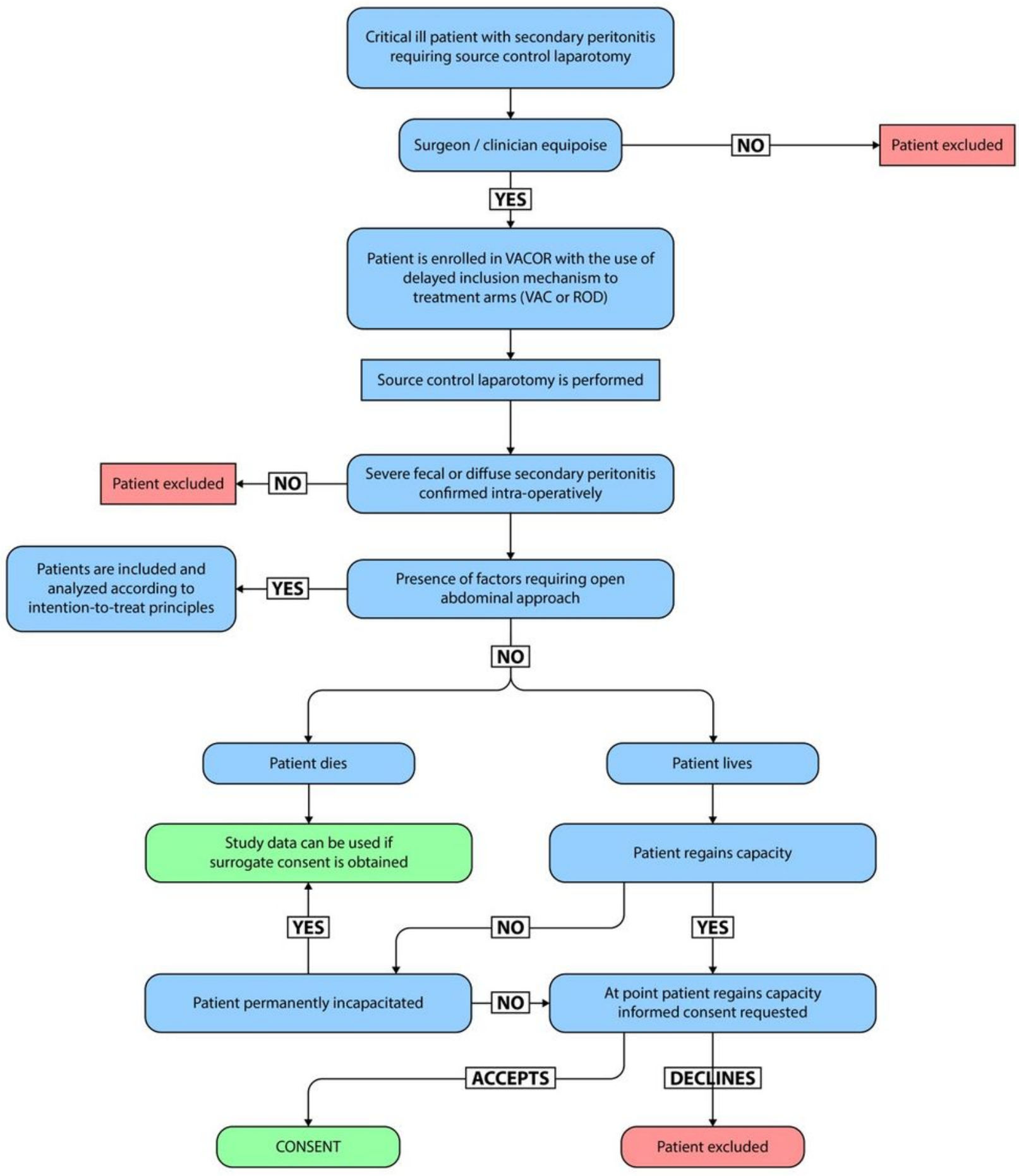

Figure 1

Flowchart of inclusion and consent 


\section{CONSORT DIAGRAM}

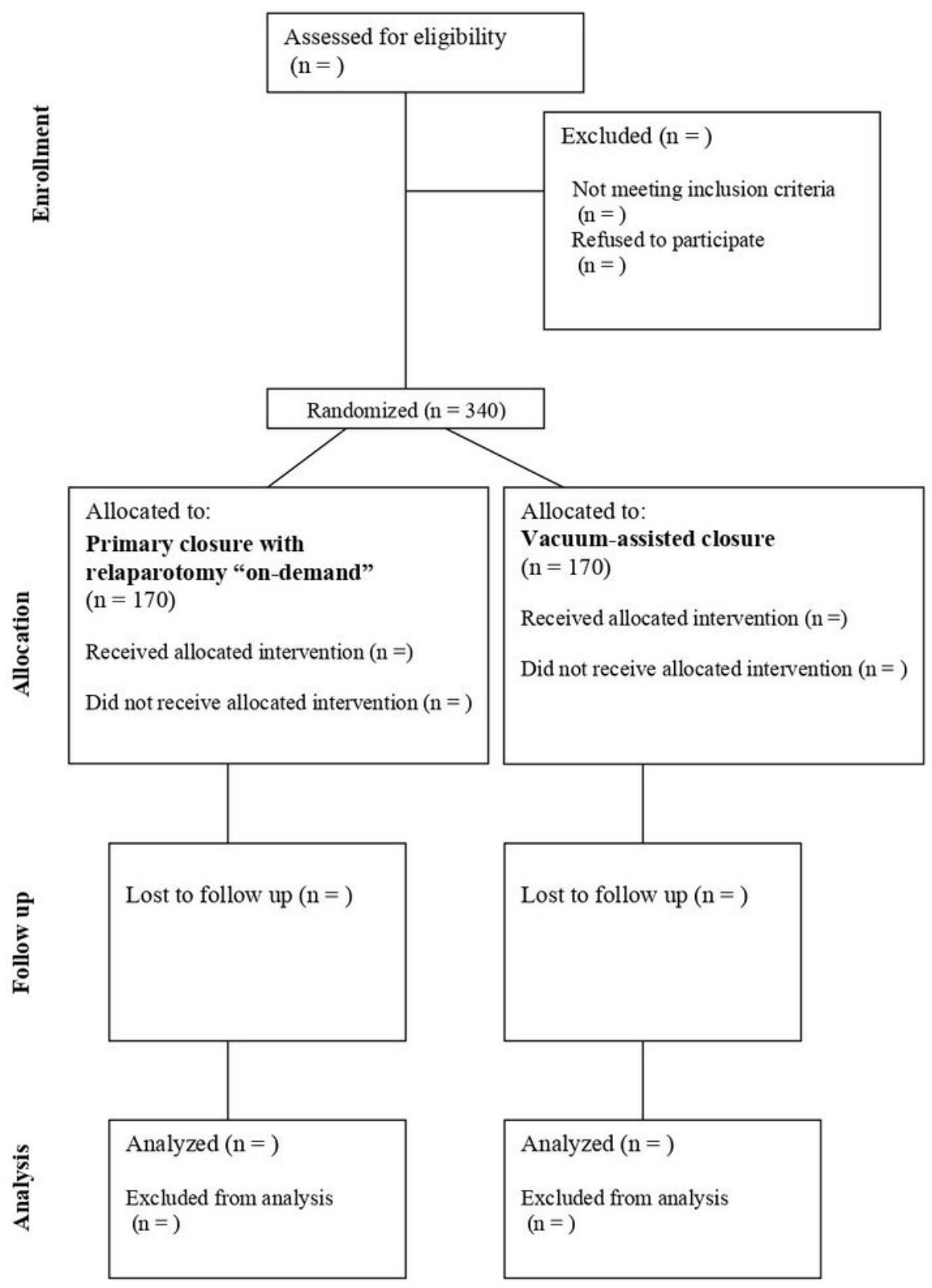

Figure 2

CONSORT flow diagram 


\begin{tabular}{|c|c|c|c|c|c|c|c|c|c|}
\hline \multirow[b]{3}{*}{ TIMEPOINT** } & \multicolumn{9}{|c|}{ STUDY PERIOD } \\
\hline & \multirow{2}{*}{$\begin{array}{c}\begin{array}{c}\text { Potential } \\
\text { subject }\end{array} \\
0\end{array}$} & \multirow{2}{*}{$\begin{array}{c}\text { Enrolment } \\
0\end{array}$} & \multirow{2}{*}{$\begin{array}{c}\text { Allocation } \\
0\end{array}$} & \multirow{2}{*}{$\begin{array}{c}\text { Post- } \\
\text { allocation }\end{array}$} & \multicolumn{4}{|c|}{ Follow-up } & \multirow{2}{*}{$\begin{array}{c}\text { Close-out } \\
5 \text { years }\end{array}$} \\
\hline & & & & & 1 months & 3 months & 1 years & 3 years & \\
\hline \multicolumn{10}{|l|}{ ENROLMENT: } \\
\hline \multirow{4}{*}{$\begin{array}{r}\text { Eligibility screen } \\
\text { Informed consent } \\
\text { Consent from } \\
\text { surgical equipoise } \\
\text { Allocation }\end{array}$} & $x$ & & & & & & & & \\
\hline & & & & $x$ & & & & & \\
\hline & $x$ & & & & & & & & \\
\hline & & $\mathrm{x}$ & & & & & & & \\
\hline \multicolumn{10}{|l|}{ INTERVENTIONS: } \\
\hline \multicolumn{10}{|l|}{$\begin{array}{r}\text { [Primary closure } \\
\text { with relaparotomy } \\
\text { "on-demand"] }\end{array}$} \\
\hline \multicolumn{10}{|l|}{$\begin{array}{r}\text { [Vacuum-assisted } \\
\text { closure] }\end{array}$} \\
\hline \multicolumn{10}{|l|}{ ASSESSMENTS: } \\
\hline \multirow{2}{*}{ [Baseline] } & & & $x$ & & & & & & \\
\hline & & & $x$ & & & & & & \\
\hline $\begin{array}{r}\text { [Operative record] } \\
\text { [Björck's } \\
\text { classification] }\end{array}$ & & & $x$ & & & & & & \\
\hline \multirow{2}{*}{ [APACHE II] } & & & & $x$ & & & & & \\
\hline & & & $x$ & & & & & & \\
\hline [SOFA] & & & $x$ & $x$ & & & & & \\
\hline \multirow{3}{*}{$\begin{array}{r}\text { [Microdialysis] } \\
\text { [Microbiological } \\
\text { sampling] } \\
\text { [Peritonitis related } \\
\text { complications] } \\
\text { [Health related } \\
\text { resource use and } \\
\text { costs] }\end{array}$} & & & $x$ & $x$ & & & & & \\
\hline & & & & & $x$ & $x$ & $x$ & & \\
\hline & & & & & & $x$ & & & \\
\hline \multirow{3}{*}{$\begin{array}{r}\text { [Clavien-Dindo] } \\
\text { [SF-36 } \\
\text { Questionnaire] }\end{array}$} & & & & & $x$ & $x$ & $x$ & & \\
\hline & & & & & & $\mathrm{X}$ & $\mathrm{x}$ & & \\
\hline & & & & & & & $x$ & & \\
\hline [1-year follow-up] & & & & & & & & $x$ & $x$ \\
\hline
\end{tabular}

\section{Figure 3}

Participant timeline

\section{Supplementary Files}

This is a list of supplementary files associated with this preprint. Click to download. 
- SPIRITFillableChecklistVACOR.doc

- VACwithfascialtractionwiththenarrowingtechnique.mp4 